\title{
Research on Submarine landslide monitoring and early warning system
}

\author{
Shanshan Yan ${ }^{1}$, Liang Xue ${ }^{1}$, Tianyang Liang ${ }^{1}$, Yankai Hou ${ }^{1}$, Hanlu Liu ${ }^{1}$, and Hongxian Shan ${ }^{1,2, *}$ \\ ${ }^{1}$ Institute of Environmental Science and Engineering, Ocean University of China, Qingdao, Shandong, China \\ ${ }^{2}$ The Key Laboratory of Marine Environment and Ecology, Ministry of Education (Ocean University of China), Qingdao, Shandong, \\ China
}

\begin{abstract}
Monitoring and early warning of submarine landslides could provide instant predictions for landslides, which is to avoid the destructive damage of submarine facilities such as pipelines and optical cable, etc effectively. However, researches on submarine landslide focus on numerical simulation and laboratory test, lacking support of in-situ observation data. This paper established the submarine landslide monitoring and early warning system by combining real-time monitoring data with web network platform and database technique. Based on the computational analysis of key monitoring parameters in the process of seabed deformation and sliding, the system has realized the accurate prediction and early warning of submarine landslides. The system has been applied to the submarine landslide monitoring in Zhoushan sea area, Zhejiang province, China, which has ensured the safety of offshore platforms and submarine projects in this area. The establishment of this system provides a new idea and method for submarine landslide warning.
\end{abstract}

\section{Introduction}

Submarine landslide refers to the geological phenomenon that the slope located on the seafloor is destabilized and damaged by its internal dynamic factors such as seismic activity, volcanic activity, active fault, or by Marine dynamic factors such as storm surge and tidal change, and moves downhill along a certain slope due to the action of gravity [1-3]. Submarine landslides can damage oil and gas exploitation platforms, pipelines, submarine communication cables, and other facilities [4-6]. At the same time, it can also cause the decomposition of natural gas hydrates, and induce wave whirlpools and tsunamis [7-11].

The monitoring and early warning of submarine landslides can effectively avoid the massive damage and reduce the loss of lives and property. However, at present, the monitoring and early warning techniques for submarine landslides are lacking. Most of the research work on submarine landslides focuses on numerical simulation and laboratory tests, which are not highly related to in-site monitoring. Therefore, it is impossible to carry out real-time early warning and prediction for submarine landslides. Peng Xiao and Anlong Li [12] used GIS technology and AHP multi-level analysis method to build a landslide risk assessment model to give early warning of submarine shallow landslides in the underwater delta of the Yellow River and made a preliminary exploration on the submarine landslide early warning.
Domestic and foreign scholars have used side-scan sonar, pressure sensor, acceleration sensor, and other equipment to monitor submarine landslides [13-15]. Saito et al. $[15,16]$ used acceleration sensors to monitor the sliding velocity of the seabed and calculated the sliding displacement of the seabed. Fabian M et al.[17,18] used a triaxial acceleration sensor and an inclinometer to monitor the lateral deformation of the seafloor, while Stenvold and Wallace et al.[19,20] used a high-precision manometer to monitor the seafloor pressure, thereby obtaining the seafloor subsidence deformation. The monitoring parameters of submarine landslides in the above studies are relatively single and have not been combined with the landslide warning work.

In this paper, the monitoring and early warning methods of land-based landslides are used for reference, and a monitoring and early warning system of submarine landslides is built by using the Web platform combined with database technology. The system can monitor the parameters closely related to submarine landslides in real-time, and set parameter threshold and early warning formula for submarine landslides. Taking Zhujiajian Sea Area of Zhoushan City, Zhejiang province, China as an example, this study conducted in-site monitoring on the potential area of submarine landslide, and combined with in-situ monitoring data, carried out early warning on the occurrence of submarine landslide.

*Corresponding author: Hongxian Shan, E-mail address: hongxian@ouc.edu.cn 


\section{Design and working principle of the system}

There are four parts in this system (Fig.1): monitoring indicators, data acquisition and transmission, system operation, and release of early warning information.

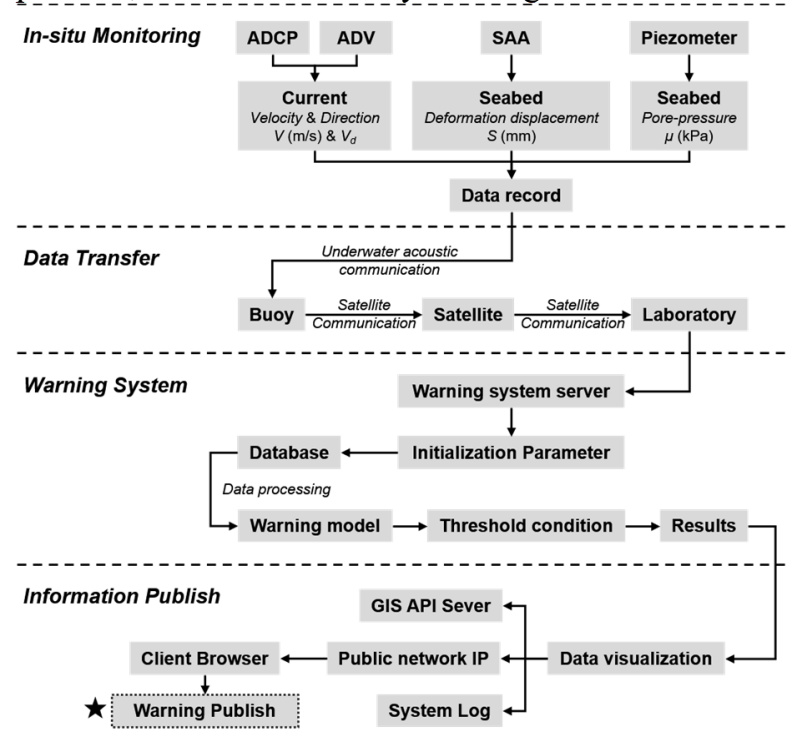

Figure 1. Principles of system structure. This system consists of four parts, here are the principles of each part, and each workflow is connected by an arrow

\subsection{Monitoring indicators}

In the part of monitoring indicators, seabed deformation and displacement, pore water pressure, wave, and tide, etc are included. Monitoring of seabed soil deformation is aimed to analyze the vertical and horizontal displacements of the slope, besides, identifying the position of discontinuity points in the displacement field, so as to identify landslides, in this way we recognize where the slide is. There is a certain relationship between seabed stability and hydrodynamics, the variation of wave load and velocity will cause the variation of pore water pressure on the seabed, while the increase of excess pore water pressure in the seabed will lead to the decrease of effective stress, the stability of the seabed would be reduced as well [21]. The influence of tides and waves lead to excess pore water pressure in the seabed, therefore, monitoring of pore water pressure and hydrodynamic plays an important indicator role in monitoring and warning of submarine landslide.

\subsection{Data acquisition and transmission}

The data acquisition and transmission part is composed of acquisition and communication equipment. The acquisition equipment includes seabed deformation and displacement monitoring system (array displacement sensor, watertight acquisition warehouse, data storage acquisition instrument), pore water pressure monitoring system (sensor, probe rod, acquisition instrument), and integrated hydrodynamic monitoring system (tidal wave instrument, Acoustic Doppler Current Profiler, and Acoustic Doppler Velocimeter). Communication equipment is mainly composed of $4 \mathrm{G}$ wireless router and transmission antenna. Data storage and acquisition devices can connect to $4 \mathrm{G}$ wireless router by peripheral extension interfaces, and plug in Ethernet and build a network to form a local or region-wide monitoring network. A real-time data transmission module is placed in the sealed cabin, in which the antenna needed for transmission is connected with the floating ball on the surface of the sea by a water-tight plug to the outside, to carry out network signal communication.

\subsection{System operation}

The submarine landslide monitoring and early warning system is divided into the front-end page system and back-end data processing and calculation system. The Tomcat server was selected to build the system and deployed on the Linux system, the Tomcat server enables connections to local resources, providing services to Java JARs and static packages on the front end and its ports can be configured directly. The server provides the front-end page display and a deployment environment for the back-end JAR packages, meanwhile, the logging system records the state of the running JAR package. By forming a map on the Linux system, the ports mapped to the Tomcat server can be accessed on the public network. At this point, the public IP can correspond to the IP on the Linux system, which means the user can access the public IP to obtain the resources on the Tomcat server. The back-end server is connected to the database, while the front-end page system is connected to the GIS API Server, and when the front-end page system calls API, it will conduct data interaction with the back-end system, the back-end system will feed back the calculation results to the front-end page for the user to consult.

\subsection{Release of early warning information}

The release of warning information is based on the monitoring data (Fig.1), parameter threshold setting and modification are provided by the system, users can view the basic information and monitoring data of the monitoring field in combination with the base map. When a monitoring indicator exceeds the threshold value, the system will automatically make a pop-up alert, or users input the warning model parameters as required, if the result is determined by the algorithm to be in danger of slipping, the system will give warning information. The hydrodynamic factor is the main initiation mechanism of submarine landslide in shallow sea area. In Xu's study [22], he calculated the sliding stability of sediments under the influence of wave cyclic load, he noticed that the shear strength determines the stability of the sediment, slip failure occurs when the shear strength of partial seabed sediments decreases to a level consistent with the critical condition of wave-induced sediment instability. In the study of $\mathrm{Wu}$ et al.[23], numerical simulation shows that when the shear stress along the slope is greater than the shear strength of seabed sediments, submarine landslides may occur in this area. 


\section{Composition of the system}

The submarine landslide monitoring and early warning system (Fig.2) consists of six parts: the login part of the system, the overview of the research area, visualization of geological environment elements, the monitoring equipment display, visualization of monitoring data analysis, and release of early warning information.

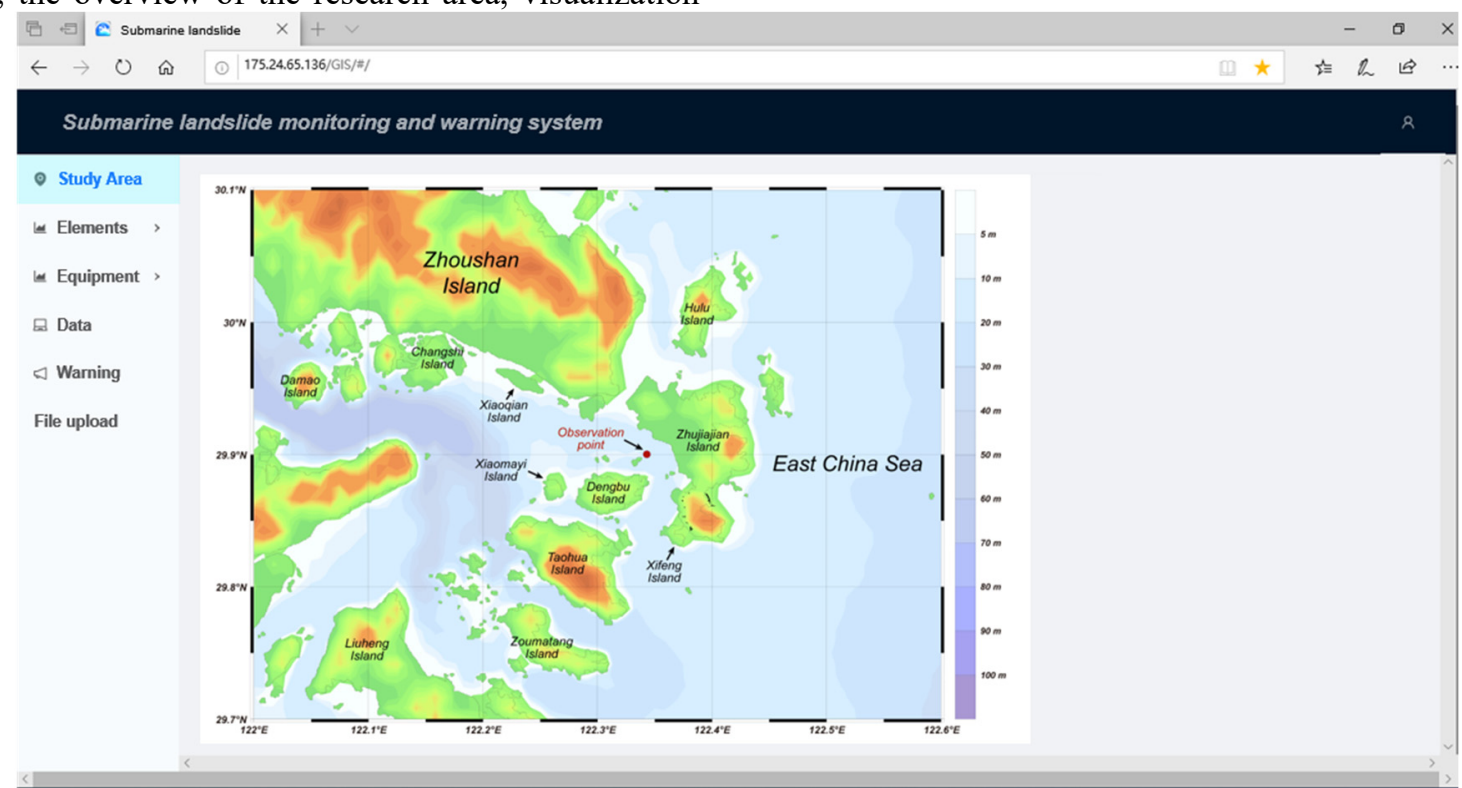

Figure 2. The user interface of the submarine landslide monitoring and warning system, here is the overview of the study area, the left content includes other functions

In the login part of the system, administrators and casual users are separated. Casual users log in the system mostly to consult the geological environment information and monitoring data of the research area, check the submarine landslide warning information, etc. The administrators can edit, delete and modify the data and chart information on the system.

The physical geographic information of the research area can be seen from the overview of the research area. This part is an embedded part in advance. When the research area is changed, the files uploaded in the implementation process can be changed, which applies to different research areas.

The visualization module of geological environment elements systematically displays the collected geological data of the research area on the interface, which can provide more standard reference materials for users, so as to get a comprehensive understanding of the area and research on submarine landslide.

The purpose of the display of monitoring equipment is to make users understand the equipment and technical parameters used in the in-situ monitoring work, and know the acquired monitoring parameters. The monitoring equipment are: seabed deformation and displacement monitoring system, pore water pressure monitoring system and integrated hydrodynamic monitoring system.

Monitoring data analysis visualization includes data uploading, data browsing, data downloading, data deleting, modification, editing, etc. In order to understand the change trend and overall situation of each monitoring parameter better, this study includes data analysis description files, which can be uploaded and analyzed by other auxiliary mapping software.
The release of early warning and forecast is the early warning about the monitoring data. The system provides the setting and modification of threshold parameters. Users can view the basic information and monitoring data of the monitoring area with the base map. When a monitoring data exceeds the threshold, the system will automatically give a pop-up box warning.

\section{Application of the system}

In this chapter, the submarine landslide monitoring and early warning system is applied in the southwest sea area of Zhujiajian Island, Zhoushan City, Zhejiang Province, China. The landslide area is located on the north-eastern slope of the tidal scour trough on the southwest side of the island, with a depth of more than $100 \mathrm{~m}$. According to the depth data of the water and multi-beam sounding data of Zhujiajian landslide, the terrain in this region is from northeast to southwest, first lower and then higher. In general, the southwest is lower than the northeast, and the terrain is concave.

The geographical coordinates of the monitoring area are: N $29^{\circ} 54$ '1 ", E 122 20' 36 "(Fig.3). In-situ monitoring of the area began on Jul 22th, 2019, and the equipment was recovered on Dec 10th to finish the monitoring task. The data analysis visualization module analyzed and displayed the in-site monitoring data during this period. The monitoring area was about $350 \mathrm{~km}$ away from the landfall of Typhoon "Lekima". The monitoring data changed significantly during the landfall of Typhoon "Lekima" (Aug 10-11th, 2019), and the analysis of the monitoring data during this period was introduced as an example. 


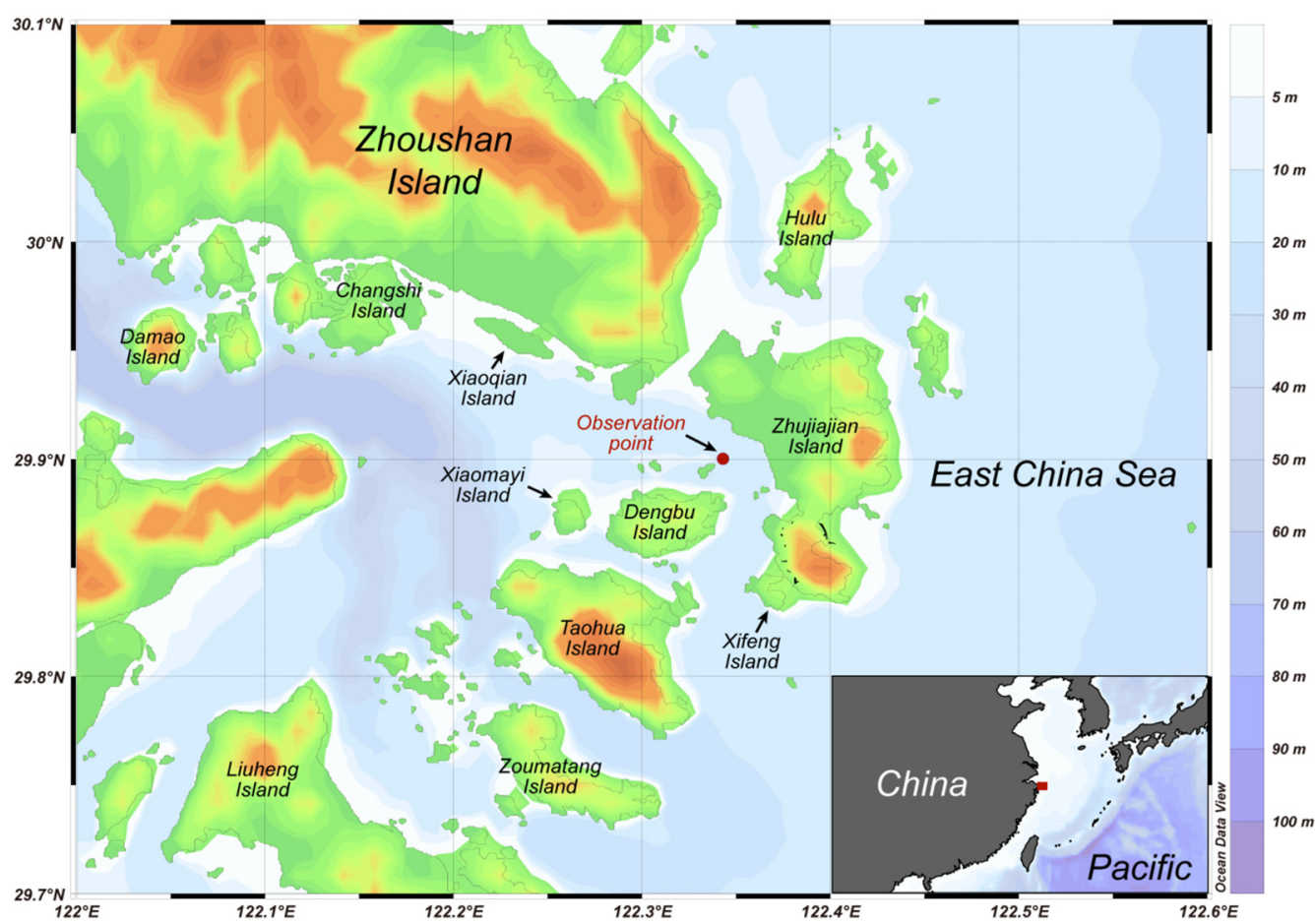

Figure 3. Monitoring stations. This figure shows the exact location of the monitoring station, and the insert shows the location of the study area

As shown in Fig. 4, under the influence of Typhoon "Lekima", the effective wave height increased significantly, rising from about $0.1 \mathrm{~m}$ under calm sea conditions to the highest $0.5 \mathrm{~m}$. Correspondingly, influenced by the change of wave intensity, the excess pore water pressure on the seabed also changes significantly. The excess pore water pressure in the shallow sediments on the seabed fluctuates significantly under the action of waves, with an amplitude of 2-4 $\mathrm{kPa}$. As a comparison, it can be seen that the excess pore pressure amplitude is about $0.5 \mathrm{kPa}$ under the calm sea condition. According to the velocity monitoring results, neap tides occurred on Aug 10th and 11th, with the maximum surface velocity of $1.07 \mathrm{~m} / \mathrm{s}$, the minimum surface velocity of $0.03 \mathrm{~m} / \mathrm{s}$, the maximum bottom velocity of $0.72 \mathrm{~m} / \mathrm{s}$, and the minimum bottom velocity of $0.01 \mathrm{~m} / \mathrm{s}$. During the observation period, there were two obvious periods: around 13:40 and 23:00 on Aug 10 th, the average surface velocity $(0.91 \mathrm{~m} / \mathrm{s})$ was significantly higher than that of the bottom velocity $(0.61$ $\mathrm{m} / \mathrm{s}$ ), indicating that the near-surface velocity was greatly affected by wind and waves.

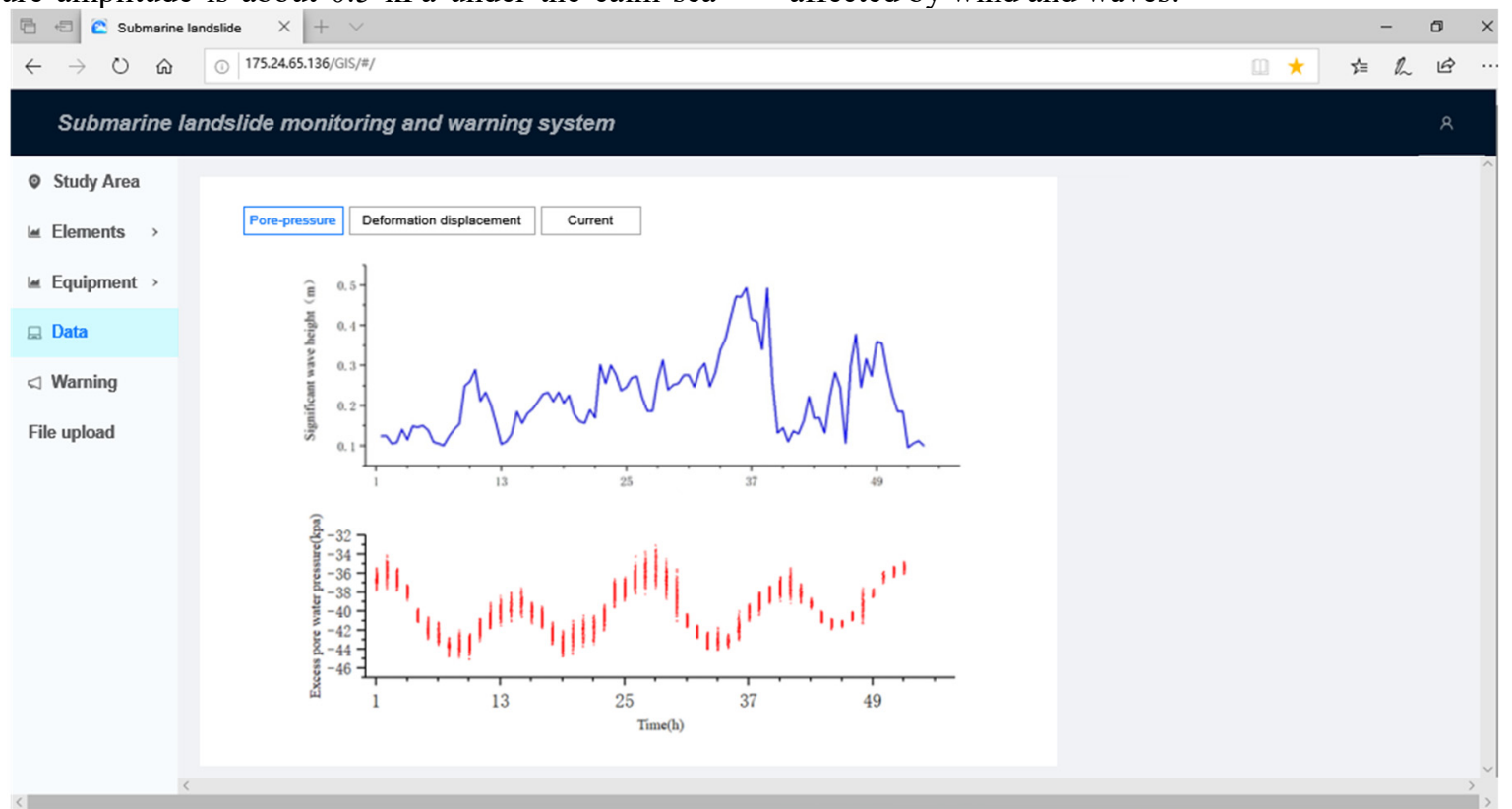

Figure 4. Data analysis of the system, the significant wave height and the excess pore water pressure on the seabed changes obviously under the influence of Typhoon "Lekima"

During the monitoring period, the maximum seabed deformation displacement was $10 \mathrm{~mm}$. After calculating the monitoring data, the system found that the shear strength of soil in this area was relatively large, and the 
system calculated that there was no submarine landslide risk in this area.

\section{Conclusions}

In this paper, a submarine landslide monitoring and early warning system was built based on in-situ observation data, the main conclusions are as follows:

(1) Based on the on-site monitoring data, the submarine landslide monitoring and early warning system has been established to realize the prediction and early warning of submarine landslide.

(2) The system's judgment of monitoring and warning results for submarine landslide is consistent with the analysis of on-site monitoring results.

\section{Acknowledgements}

This work was supported by the project of National Natural Science Foundation of China (41877223): Research on initiation process and controlling factors of submarine landslide in Yellow River underwater delta based on in-situ observation. I would like to extend my deep gratitude to my senior fellow apprentices Tian Chen, Fang Lu, Zhihan Fan, and Zhiwen Sun, who offered me pratical cordial and selfless support in writing this manuscript.

\section{References}

1. M.A. Hampton, H.J. Lee, J. Locat, Rev Geophys, 34, 33-59, (1996)

2. J. Locat, H.J. Lee, Can Geotech J, 39, 193-212, (2002)

3. G.H. Hu, Z.X. Liu, J.W. Fang, Advances in Marine Science, 24, 130-136, (2006)

4. .Maslin, Mark, Mikkelsen, Geology, 26, 1107, (1998)

5. G. Dan, N. Sultan, B. Savoye, Mar Geol, 245, 40-64, (2007)
6. Q.L. Yang, Journal of Ocean Technology, 4, 65-67, (1994)

7. C.K. Paull, W.J. Buelow, W. Ussler, Geology,24, 143-146, (1996)

8. H.Y. Gan, J.S. Wang, G.W. Hu, Journal of disaster prevention and mitigation engineering, 24, 177-181,(2004)

9. X.T. Peng, H.Y. Zhou, G.Q. Chen, Journal of Natural Disasters, 11, 18, (2002)

10. H.X. Weng, Y.Y. Xu, Z.S. Lou, Journal of Zhejiang University. Sciences Edition, 47, 588-594+600, (2006)

11. H.B. Song, Progress in Geophysiscs, 3, 503-511, (2003)

12. P. Xiao, A.L. Li, Geological Science and Technology Information, 35, 226, (2016)

13. T. Yokoyama, M. Shimoyama, S. Matsuda, K. Tago, J. Takshima, Tenth ISOPE Ocean Mining and Gas Hydrates Symposium. (2013)

14. J.G. Moore, D.A. Clague, R.T. Holcomb, J Geophys Res-Sol Ea, 94, 17465-17484, (1989)

15. H. Saito, T. Yokoyama, S. Uchiyama, OCEANS,(2006)

16. Y. Awashima, H. Saito, T. Hoaki, S. Sawada, T.Fukasawa, S. Sukizaki, Y. Ishihara, K. Kano, N. Arata, OCEANS, (2008)

17. M. Fabian, H. Villinger, GEOCHEM GEOPHY GEOSY, 9, 2008

18. M. Fabian, H. Villinger, Mar Geophys Res, 28,13-26, (2007)

19. L.M. Wallace, S.C. Webb, Y. Ito, M. Kimihiro,Science, 352, 701-704, (2016)

20. T. Stenvold, O. Eiken, M. Zumberge, G. Sasagawa, S. Nooner, Spe Journal, 11, 380-389, (2006)

21. Z.H Wang, Y.G. Jia, X.L. Liu, W. Wei, X.L. Wang, S.T. Zhang, H.X. Shan, Periodical of Ocean University of China, 47, 104-112, (2017)

22. G.H. Xu, D, 2006

23. S.G. Wu, S.S. Chen, Z.J. Wang, Geoscience, 22,430-437, (2008) 